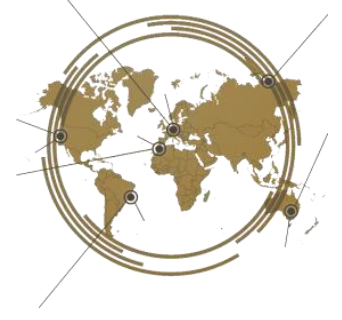

\title{
Internal continuatives and logical metaphors: A development of classifying conjunctive relation
}

\author{
Riyadi Santosa ${ }^{1}$, Sumarlam ${ }^{1}$, Tri Wiratno ${ }^{1}$, Agus Dwi Priyanto ${ }^{1}$, Ratna Susanti ${ }^{2}$ \\ ${ }^{1}$ Faculty of Cultural Sciences, Universitas Sebelas Maret Surakarta, Indonesia \\ ${ }^{2}$ Politeknik Indonusa Surakarta, Indonesia
}

This research attempts to develop Martin's \& Rose's concept of conjunctive relation (CR) analysis, in which the external and internal roles of conjunction do not include the other two types of conjunctive relation markers such as continuative and logical metaphor. Relying on more than twenty international journal articles, the research findings exhibit that certain types of continuative and logical metaphor can not only operate externally to connect events and qualities but they can also function internally to organize evidences and arguments in texts. As a result, not only a new role of internal continuative and logical metaphor can be confirmed, but the findings will also introduce an elaborated development of classifying $C R$ in general. The emergence of the internal role of continuative and logical metaphor leads to a more elaborate way of connecting and grouping clauses into different units of discourse. In this way, they will also be able to demonstrate how texts can be built up through clauses, phases, and stages in a particular genre, without the need to be interpreted in conjunctions.

Keywords: external, internal, conjunctive relation, genre, stage, phase

\section{INTRODUCTION}

OPEN ACCESS

ISSN 2503 3492(online)

${ }^{*}$ Correspondence:

Riyadi Santosa

riyadisantosa1960@gmail.com

Received: 28th June 2021 Accepted: 22th September 2021

Published: 1st November 2021

Citation:

Santosa. R., Sumarlam. M, Wiratno.T., Priyanto A.D., Susant $i$

R. (2021).

Internal continuatives and logical metaphors: A development of classifying conjunctive relation.

J.Eng.Educ. Society. 6:2.

10.21070/jees.v6i2.1360
There are different concepts of looking at conjunction across schools of linguistics. Structural linguists, for example, perceive conjunction as unit of linguistics that connect groups, clauses, and sentences. They have only a little concern on the operation of conjunction beyond clauses and sentences in a discourse level, since their highest level of linguistic data is sentence (Santosa et al., 2011). Meanwhile, cognitive linguists focus on how forms and meanings of conjunction cognitively link two units of clauses, sentences, and units of discourses. They still ignore their discussion on the role of conjunction in building up higher units of linguistics such as activity sequences in the field of discourse (Santosa et al., 2011). Expanding Halliday's ideas of logico-semantic relation in clause complexes, (Halliday \& Matthiessen, 2013) development of further categories of elaborating, extending, and enhancing ends at the level clause complex analyses and conjunctive adjunct connecting different sentences. Although other research on conjunction begin to see the relations between the use of certain types of conjunction and types of genres or between thematic progression and conjunction in multimodal texts, they still fall on listing the forms and meanings of use of conjunction in the sentence levels of different genres. As a result, they analyze conjunction in a discrete operation so that they cannot 
demonstrate how conjunction can connect units of discourse to build activity sequences in the field of discourse ((Alyousef, 2016). Realizing the inadequacies of such concept of conjunction to be operated in discourse semantics, Systemic Functional Linguistics develops the meaning-based logical devices that can connect events and qualities externally outside discourses and that can organize the discourses in a smooth and clear waves of information. Such logical devices that base their operations on meanings and functions in discourse semantics are called conjunctive relation $(\mathrm{CR})$. The discourse logical markers includes conjunction, continuative, and logical metaphor (James R Martin, 2014). By such devices, SFL can demonstrate how clauses are knitted into phases and stages; and they can also identify certain patterns of stages of a particular activity sequence reflecting a genre (Santosa et al., 2011).

However, problems still arise particularly in how the conjunctive relation devices function and operate in a field of discourse since Martin \& Rose (2007) claim that only conjunction can connect externally and internally in the field of discourse and no continuative and logical metaphors are said to have the same function as that of conjunction (Martin \& Rose, 2007). However, in a small number of data, Santosa (2011) found evidence that continuative and logical metaphors can both operate externally as well as internally similar to what conjunction can do.

Thus, this study is, first, aimed at justifying how continuative and logical metaphor can operate externally to connect events and qualities outside texts and internally to organize the flow of discourse in a more extended and abundant data of journal articles. In this way, this will produce a different way of classifying conjunctive relation in general. Secondly, this study is also attempted to demonstrate how certain types of continuative and logical metaphor can knit clauses into phases and stages of a genre, without being interpreted as conjunctions.

The term of conjunctive relation (CR) is an expansion of a technical term for conjunction. It unfolds logical relation connecting activity sequence in the field of discourse (James $\mathrm{R}$ Martin, 2014). Basically, the forms and meanings are constructed and determined from both processes in syntactic and paradigmatic resources in discourse semantics. Different from structural, cognitive linguistics' concepts on conjunction (Santosa et al., 2011), and functional grammar's concepts of conjunctions and conjunctive adjuncts (Halliday \& Matthiessen, 2013), CR does not only work between clauses but it also operates above clauses and groups of clauses in a discourse semantic level. It is realized in three different linguistics units that involve conjunction, continuative, and logical metaphors. The forms, meanings, and functions are built up in how they operate within a field of discourse. Instead of connecting linguistic forms such as groups of lexes or clauses, $\mathrm{CR}$ devices rather connect externally experiential meanings of discourse such as events, qualities, and ideas in spatial, temporal, or consequential activity sequences. Besides, CR also organizes the flow of information in a discourse (James R Martin, 2014), which is later developed in phases and stages of genres. Thus, CR will develop the discourse structure in its own right through its explicit and implicit realization (Martin, 2014).

Below and between sentences, external and internal functions of conjunctions are introduced. The introduction of external and internal roles of conjunction opens the way for discourse analysts to depict how CR operates in a discourse level (Martin \& Rose, 2007). External conjunction operates outside texts to connect events and qualities. Internal conjunction organizes arguments, evidences, and conclusion between clauses and between groups of clauses to produce phases and stages of genres (Santosa et al., 2011; Taboada, 2011).

External conjunction expresses four major types of meanings: adding, comparing, ordering, and consequencing events and qualities of the external world of texts, in which each type has further detailed taxonomy of meanings. For example, addition can be further classified as additive and alternative; comparison can be classified as similar and different, time is categorized as successive and simultaneous, whereas consequence is further categorized as cause, means, condition, and purpose. Complete resources of detailed classification of external conjunction can be seen in Martin and Rose (J.R. Martin \& Rose, 2007).

Internal conjunction also expresses four major types of meanings: adding, comparing, ordering and consequencing evidences, arguments, conclusion. Since it organizes evidences, arguments and conclusions, each category is further sub-classified differently from that of external conjunction. Addition develops and stages arguments or evidences. Comparison compares and contrasts similar and different evidences, arguments. Time orders and coincides evidences and arguments, whereas consequence justifies, counters evidences or arguments and concludes arguments. Complete resources of detailed classification of internal conjunction can be seen in Martin \& Rose (J.R. Martin \& $\underline{\text { Rose, 2007). Both external and internal conjunction unpack }}$ logical relations into complex clauses that are mostly realized in non-relational processes (Santosa et al., 2011).

The next type of conjunctive relation devices is continuative. It is a particle attached in verbal group, which tells us about addition, comparison and time. There has been so far no consequences found in continuatives in English (J.R. Martin \& Rose, 2007). Different from conjunctive adjunct, resembling conjunctions connecting previous or succeeding clauses and sentences (Halliday \& Matthiessen, 2013), continuative can only work externally in the field of discourse. The meanings of addition, comparison and times are also sub-classified externally in a number of categories, such as: neutral addition, neutral, less than, more than comparisons, and sooner, longer, persistent, repetitive times. Complete resources of English continuatives can also be found in (J.R. Martin \& Rose, 2007). 
The last type of conjunctive relation devices is logical metaphor. It is a logical relation realized in units of linguistics other than conjunctions and continuatives. It operates in experiential constituents in transitivity. It is a logical reality realized in grammatical metaphors such as, in process, circumstance, and participant or thing. Logic as process operates as verbal group in predicator of a clause. It is usually realized verbs such as make, cause, affect, influence and others. Logic as circumstance is realized in a prepositional phrase in adjunct such as: as result of..., due to..., in relation to... and others. As circumstances of transitivity, it realizes eight different types of circumstances (Halliday \& Matthiessen, 2013), but, logically, it expresses mostly the meanings of comparison, time and consequence (Santosa et al., 2011; Dreyfus \& Bennett, 2017). Logic as participant is realized in a nominal group functioned as subject or complement slots in a clause. It is usually realized in nouns or nominal groups such as the first time, reason, condition, and others. Thus, it experiences nominalization, packing logic, which is congruently realized as conjunction, into things or participants. Functionally, it can also be used to demonstrate how science discourse necessarily involves grammatical metaphor in building technical terms, relating causal relationship, and organizing text (James R Martin, 2014). The meanings vary from logic as process, logic as circumstance, to logic as participant, involving addition, comparison, times and consequence (J.R. Martin \& Rose, 2007). Similar to grammatical metaphors, these logical metaphors also pack the logical relations in complex clauses into more compact and dense constructions of simplex clauses of attributive or identifying relational processes (Devrim, 2015).

Another important reality to be considered in analyzing conjunctive relation is that it cannot only be realized explicitly through conjunction, continuative, and logical metaphor in the field of discourse. But, the slots of logical relations can be left blank and let readers interpret implicitly the relations between the functional elements in clauses and groups of clauses through their contexts. Thus, they implicitly still function to connect events or arguments in the field of discourse. The whole concepts of Martin \& Rose's conjunctive relation/CR (J.R. Martin \& Rose, 2007) can be interpreted in the Figure 1, where external and internal roles or functions of CR are only attached on conjunction. Figure $\underline{1 .}$

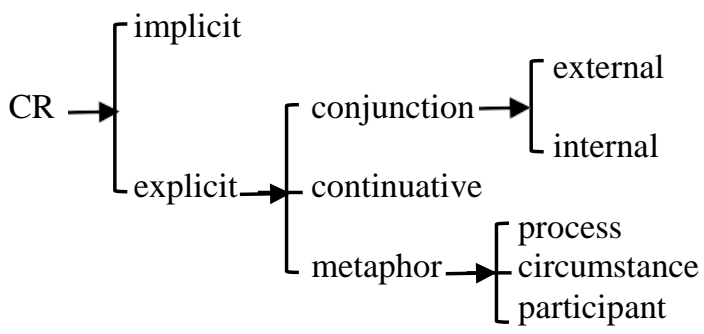

Figure 1: Types of CR devices by Martin \& Rose (J.R. Martin \& Rose, 2007)
In the operation of text analysis, the external and internal functions of conjunction will be cross-checked with the four types of meanings of conjunction: addition, comparison, time, and consequence. The general resources of external and internal functions of conjunction can be summarized in Table1. The external conjunction connect events and qualities outside texts by addition, comparison, time, and consequence. Meanwhile, internal conjunction organizes the flow of arguments or evidence in texts by addition, comparison, time, and consequence. The complete resources of external and internal conjunction can be found in Martin and Rose (J.R. Martin \& Rose, 2007). Table 1.

Table 1 | External and Internal Functions of Conjunction

\begin{tabular}{lll}
\hline $\begin{array}{l}\text { Conjunction } \\
\text { Addition }\end{array}$ & $\begin{array}{l}\text { External } \\
\text { Additive and } \\
\text { alternative }\end{array}$ & $\begin{array}{l}\text { Internal } \\
\text { Developing } \\
\text { and staging }\end{array}$ \\
Comparison & $\begin{array}{l}\text { Similar and } \\
\text { different }\end{array}$ & $\begin{array}{l}\text { Similar and } \\
\text { different }\end{array}$ \\
Times & Successive & Successive \\
& and & and \\
simultaneous & simultaneous \\
Consequence & Cause, means, & Concluding \\
& purpose, & and \\
& condition & countering
\end{tabular}

Source: (J.R. Martin \& Rose, 2007)

In the analysis of conjunction between clauses and groups of clauses, the external function of conjunction is coined as left-facing arrows [ $\$$ ]. The internal function of conjunction is symbolized as right-facing arrow [ $\mathbf{Z}$ ]. Meanwhile, those that connect groups of clauses representing phases or stages, both external and internal arrows will go up straight to connect to all of the covered clauses [ [ ] and [ ] (J.R. Martin \& Rose, 2007). The explicit conjunction will be written in bold letters, where the implicit conjunction will be written bold and parenthesized. All of the smallest sub-classifications of meanings are abbreviated due to practical reasons and economizing spaces (Santosa et al., 2011).

The systemic use of implicit and explicit CR unfolding in texts can only be seen through their contexts of uses, involving the contextual configuration of field, tenor, and mode of discourse as well as through understanding the higher contexts involving types of genres as a representation of culture (J.R. Martin \& Rose, 2007). In relation to the use of $\mathrm{CR}$, field displays how conjunctive relation connects and knits experiences in a discourse, whether it expands the meanings of clauses or groups of clauses in the field of discourse through elaboration, extension or enhancement (Halliday \& Matthiessen, 2013). Tenor accommodates interpersonal meaning in which conjunctive relation is used for in a discourse, and mode provides a semiotic space where and how the experience and social relation are connected and knitted by conjunctive relation in a discourse. 
This contextual configuration of the three aspects of contexts will produce a particular type of use in a discourse, or what the systemic linguists call it register, where meanings and functions originate (Martin et al, 2010; Santosa, 2011; Taboada, 2011; Hasan 2014). In this way, the configuration of meaning will produce language variation along the cline of phonology or graphology, lexicogrammar and discourse semantics within context of culture and context of situation (Lecompte-Van Poucke, 2016). The register or functional variation of language (Matthiessen, 2015a \& b; Matthiessen \& Khasyaf, 2014) used in some particular type of context includes the use of CR that develops generic structure potentials (GSP) or other functional linguist may also call it rhetorical structure (Stuart-Smith, 2007), which indicates, first, obligatory and optional elements, second the order in sequence of the functional elements, and third, possibility of recursion or reiteration of the GSP (Hasan, 2014). Thus, the concept of GSP unfolds the higher level of semiotic resource, genre.

Genre is a type of culture recurring in a society, building up a pattern of a social process as a way of recognizing, responding to, acting meaningfully and consequentially within, and helping to reproduce the pattern (Liddicoat, 2009). It pursuits a goal of a particular social process, in which the goal is achieved through stages (Martin \& Rose, 2007; Martin et al, 2010; Santosa, (2011). The stages may comprise of phases or a phase, developed from clauses, which are connected and grouped by CR (Martin \& Rose 2007; Santosa et al, 2011; 2014; 2016). This concept also reflects that genre represents recurring human activities in a culture reflecting their encoding and decoding intertextuality (Nababan et al, 2016).

\section{METHODS}

This research belongs to a descriptive, qualitative, and case study with a SFL discourse analysis approach (Grbich, 2007). It locates internet sites involving twenty different articles of internationally indexed journals.

This non-geographic and non-demographic location can still project the three basic elements of location, including situation, participants, and events through of $\mathrm{CR}$ when connect events and qualities and organizes information in texts (Spradely, 2007). The collected texts represented the source of data, whereas the use of conjunctive relation in their textual organizations were taken as primary data. Thus, the data will realize the use of CR in connecting events, participants, settings, and observed behaviors (Spradely, 2007). Criterion-based sampling technique was applied to satisfy the purposes of this research, involving criteria such as the availability of data of all types of forms, meanings, and functions of conjunctive relation in the texts. The analysis was done by doing content analysis involving domain, taxonomic, componential analyses and finding cultural values. Domain analysis unfolds the structure of social processes where and when CR is used. Taxonomic analysis identifies the types of CR used in the texts. Componential analysis combines domain and taxonomic analyses to produce matrical relations between domain and taxonomy to find out patterns of uses in their contexts. Finally, the patterns are interpreted and discussed in their contexts of use, theoretical framework, and previous research to find out the transferability of the findings (Spradely, 2007).

\section{RESULTS AND DISCUSSION}

This section will not discuss all meanings and functions of the types of $\mathrm{CR}$, conjunction, continuative, and metaphor found in the data. This section will only discuss continuative and logical metaphor, particularly those functioning as external and internal CR. This is because all of the external and internal conjunction and the external continuative and logical metaphor operate similarly as discussed in Martin \& Rose (2007). Since the focus of this study is to demonstrate how the internal continuative and logical metaphor can operate in the field of discourse, then their appearance in the studied texts will be displayed and discussed elaborately in this section.

The interesting thing to exhibit in this section is that not all types of continuatives and logical metaphors can play internally in the field of discourse. Among three types of continuatives found in English, addition, comparison, and time (Martin \& Rose, 2007) only neutral addition also can operate both externally and internally in the field of discourse in the data. Similar to Martin and Rose ( 2007) findings, continuatives such as neutral, less than, more, than comparison, and sooner, longer, persistent, and repetitive time continuatives can operate externally in the field of discourse in the data (see Table 2).

Table 2 | Function of continuative

\begin{tabular}{|c|c|c|c|c|}
\hline Types of & Expectanc & Example & \multicolumn{2}{|c|}{ Function } \\
\hline Continuatives & $\mathrm{y}$ & & Ext & Int \\
\hline Neutral & Neutral & Also & $\sqrt{ }$ & $\sqrt{ }$ \\
\hline Addition & Neutral & too, as well & $\sqrt{ }$ & \\
\hline Comparison & Neutral & so (did he) & $\sqrt{ }$ & \\
\hline & Less than & only, just & $\sqrt{ }$ & \\
\hline & More than & Even & $\sqrt{ }$ & \\
\hline Time & Sooner & Already & $\sqrt{ }$ & \\
\hline & Longer & finally, at last & $\sqrt{ }$ & \\
\hline & Persistent & Still & $\sqrt{ }$ & \\
\hline & Repetitive & Again & $\sqrt{ }$ & \\
\hline
\end{tabular}

In larger data, persistent, repetitive, and longer time continuative and more than and less than comparison continuative may be potentials of functioning internally in the field of discourse. The following examples show that neutral 
addition also, less than comparison only, persistent time still, and repetitive time again continuatives perform externally to connect events and qualities outside texts.

Despite the fact that Trebits' (2009) research is not focused on academic language, it is discussed here since she found significant differences in the conjunctions used in European Union (EU) documents and the British National Corpus (BNC). While the Iranian group had eleven proceedings at the conference, their cumulative number of words (10229) was slightly higher than the total number of words in the group of Persians in Malaysian universities, which had twelve proceedings (9129). The difference between the two groups can also be seen in the mean number of words, which is 930 words for Iranian universities and 760 words for Malaysian universities, respectively.

Only coordinating phrase conjunctions and logicalsemantic conjunctions are related to the ongoing study among these cohesive connections. Though the background song in the 6th subset was in a language unknown to the participants, it still posed the same level of interference as the background message in the subset 1 . Prior to the segment analyzed, MM mentioned the ipad during the meeting and SM brings it up once again for the purpose of ridiculing MM.

In the first example, also connects events externally in two different events. The external continuative adds it is reviewed here to the previous explanation because she revealed significant differences between the conjunctions used in European Union (EU) documents and the British National Corpus (BNC). Meanwhile, in the second example, the mean for the number of words likewise reveals this difference between... and the first event that the proceedings varied in terms of the number of words even... In contrast, in example 3, the less than comparison continuative merely limits the study to include coordinating phrase conjunctions and logical-semantic conjunctions. The persistent time in clause 4 expresses unexpected activity in posing the same level of interference... Finally, the repetitive time again repeats the event that SM brings it up once again for the purpose of ridiculing MM.

On the other hand, in the following examples also adds internally an argument to the previous clause. For example: (1) The data of this study are confined to the conference proceedings. Other elements of cohesion, such as referential and lexical cohesion, will be studied to improve the description of cohesion in Persian academic writing. The findings may also be useful in the teaching and learning of English for academic purposes. (2) Through repressive humour, the team members of the higher ranking gain compliance by getting other participants to agree with their views and conform to their instructions. The use of repressive humour also helps to tone down directives thus minimising the face threatening acts of the interlocutor. (3) Yet, apart from the positive functions, humour also possesses negative functions that are often deemed to disrupt the flow of work, slow down productivity and waste time
(Porcu, 2005). In a workplace setting, humour can function as a boundary marker that is covertly used to assign colleagues who conform or deviate from shared social norms. Humour can be a double-edged participants from 'in group' members during discussions. sword where it functions to involve or stray.

Internal neutral addition continuative also is most commonly used in discussion and conclusion of journal articles. In example 6, also adds an argument, The findings can also contribute to the teaching ...., to the previous argument developed by the writer, Researching other aspects of cohesion, ....will enhance the description of cohesion .... (Naderi et al, 2013). Meanwhile, in the example 7, the writer adds an argument, The use of repressive humour also helps to tone down directives...to the previous argument, Through repressive humour, the team members of the higher ranking gain compliance by getting other participants .... (Jan \& Omar, 2013). However, the internal continuative also can also be found in the introduction when the researcher reviews related articles to find research gaps. Example 8 indicates the case, the internal continuative also adds the positive functions of humors with the negative functions that are often deemed to disrupt the flow of work, slow down, productivity and waste time. Thus, it can be concluded that also can function both externally and internally in the field of discourse, depending on the experiential or textual realities it connects (Santosa, 2011). Secondly, similar to continuatives, the three types of logical metaphors, structurally, may have the potentials to operate both externally and internally (Santosa, 2011). However, the data indicate that only one type of logical metaphor, logic as process, can execute both external and internal roles of CR.

The other types of logical metaphors, logic as thing and logic as circumstance, can only work externally in the discourse semantics. For example: (1) The authors believe that students' excessive usage of connectors arises from their inability to correctly connect ideas through lexicalization. (2) Their research indicated that Pakistani students overuse conjunctive ties in academic writings due to their limited understanding of logical relationships and their mothertongue reference. (3) As a result, the researchers reached the conclusion that the employment of conjunctive components is influenced by local academic discourse as well as cultural backgrounds.

The three examples of logic as thing in example 8, logic as circumstance in clause 9, and logic as process in clause 10 , operate externally to explain why the events happens that ways. Logic as thing the result in example 8 connects an expected effect, the overuse of connector by the students, with the cause, their inability to appropriately connect the concepts through lexicalization. Logic as circumstance because of ... in example 9 also realizes a causal relation where massive overuse of conjunctive ties in academic texts by Pakistani students is an effect whereas their limited competence in logical relationships as well as their mother tongue interference is the cause. The case is 
also the same in example 10. The logic as process is affected demonstrates a causal relationship between the impact of the conjunctive element and the cause the local academic environment's discourse as well as cultural backgrounds.

Thus, by adding examples in clause 11 and 12, logic as processes both will enhance in clause 11 and can ... contribute to in clause 12, all examples of logical metaphors from 7-11 work externally as expectant cause consequence to indicate causal relationship, which pack the events into phenomena structured in token and value constructions (Halliday and Matthiessen, 2014; Santosa, 2011).

1. Other elements of cohesion, such as referential and lexical cohesion, will be studied to improve the description of cohesion in Persian academic writing.

2. The results may be beneficial to the teaching and learning English for academic purposes.

Meanwhile, logic as verbal processes, functioning as projecting clauses in the projection (Halliday \& Mattiessen, 2014; Martin et al, 2010), such as could be said in clause 14, could be deduced in clause 15 , can be claimed in clause 16, and can be inferred in clause 17, operate internally as concluding consequence to conclude the both side arguments in the previous discussion. They attempt to realize the writer's points, principles, grounds, possibilities of the preceding arguments as propositions (Halliday \& Matthiessen, 2014).

1. Other elements of cohesion, such as referential and lexical cohesion, will be studied to improve the description of cohesion in Persian academic writing

2. The results may be beneficial to the teaching and learning English for academic purposes.

3. It can be claimed that two or three known word context are still as small as one word context and they do not have differing contextual roles.

4. Therefore, with regard to the last research question, it can be inferred that the students have an overall optimistic view toward learning English.

In addition, logic as attributive relational process functioning as projecting clause can also operate as internal logic as process, expressing the writer's justification and conclusion (Halliday \& Matthiessen, 2013). The following examples is true in clause 18 justifies the previous proposition that shifting from teacher-reliance to selflearning, the students may not be ready to embrace this new learning culture, whereas is apparent in clause 19 concludes the use of an on-line writing program. (1) It is true that shifting from teacher-reliance to self-learning, the students may not be ready to embrace this new learning culture. (2) It is apparent that the use of an on- line writing program does help the teachers with their daunting job in giving feedback.

Meanwhile, the logic as identifying relational process as projecting clause means elaborate the previous proposition as in internal rework similar comparison. This means that an on-line writing program should be integrated with the teachers' intervention in the students' writing process. In addition, logic as process in the projecting clause can also function as offering suggestion or recommendation as proposals (Halliday \& Matthiessen, 2013). This type of logic as verbal process, in fact, indicates abundant appearances in essays and journal articles (Ignatieva \& Rodríguez-Vergara, 2015). For example: (1) Thus, this study suggests that the scoring should be regarded with caution, not only by seeing it as a MY Access scoring system constraint but also by seeking a deeper understanding of EFL writing philosophy. (2) To make use of the findings of this research, I recommend that apart from morphological analysis, teachers should encourage students to integrate other vocabularylearning. (3) It is hoped that such studies can help attract more attention toward this crucial issue and by creating the right kind of facilities and situations students can use their abilities.

Logis as verbal process functioning as projecting clause suggest in clause 21 as well as recommend in clause 22, and logic as mental process in a projecting clause is hoped in clause 23 consecutively realize internal conclude concluding consequence as proposal (Halliday \& Mattiehessen, 2014).

It is quite apparent that the data indicate that internal neutral addition continuatives and internal logical metaphor as process such as attributive, identifying, and verbal processes as projecting clauses can elaborate evidences, develop, justify, and conclude arguments. However, the external continuative and logical metaphors will connect events and qualities as addition, comparison, time, and consequence. Thus, they have different function or roles in developing the field of discourse. Thus, it is also clear that the findings can justify the hypothesis that parts of continuative and logical metaphors as process can operate externally and internally in the field o discourse. Therefore, there is a possibility of modifying Martin's and Rose's classification of CR in terms of their functions (2007) that the role or the function of CR may not only be applied to conjunction, but it can also classify the role of continuative and logical metaphor although not all types of continuative and metaphors can apply the role.

Then, the following Figure 2 may reflect the case.

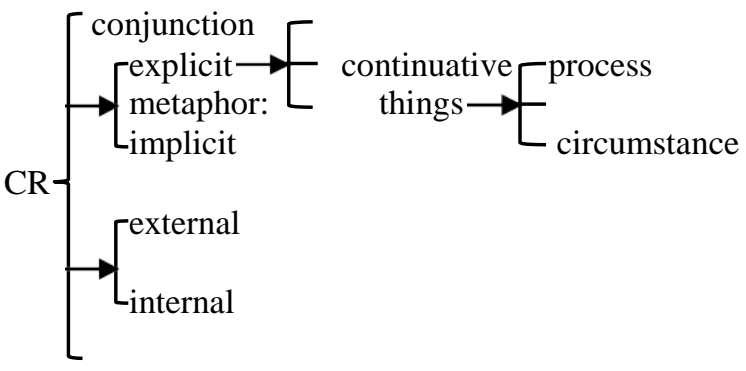

Figure 2: Modified Martin \& Rose's classification of CR

Based on the modified classification of CR in Figure 2, it can be drawn that continuative and logical metaphor can operate themselves to connect events and organize texts without being interpreted as implicit conjunction as what 
Martin and Rose do (2007). To realize the complete analysis of CR in helping develop activity sequence in the field of discourse, all explicit and implicit CR are printed bold, functioning as both internal and external conjunction (Santosa, 2010;) (Martin \& Rose, 2007; Santosa, 2010; 2011). Meanwhile the meanings of each CR are abbreviated as to brief and economize the space. The example of the analysis can be seen in Figure 3, displaying how external and internal CR operate in a text by analyzing Lee's abstract of his article (2012).

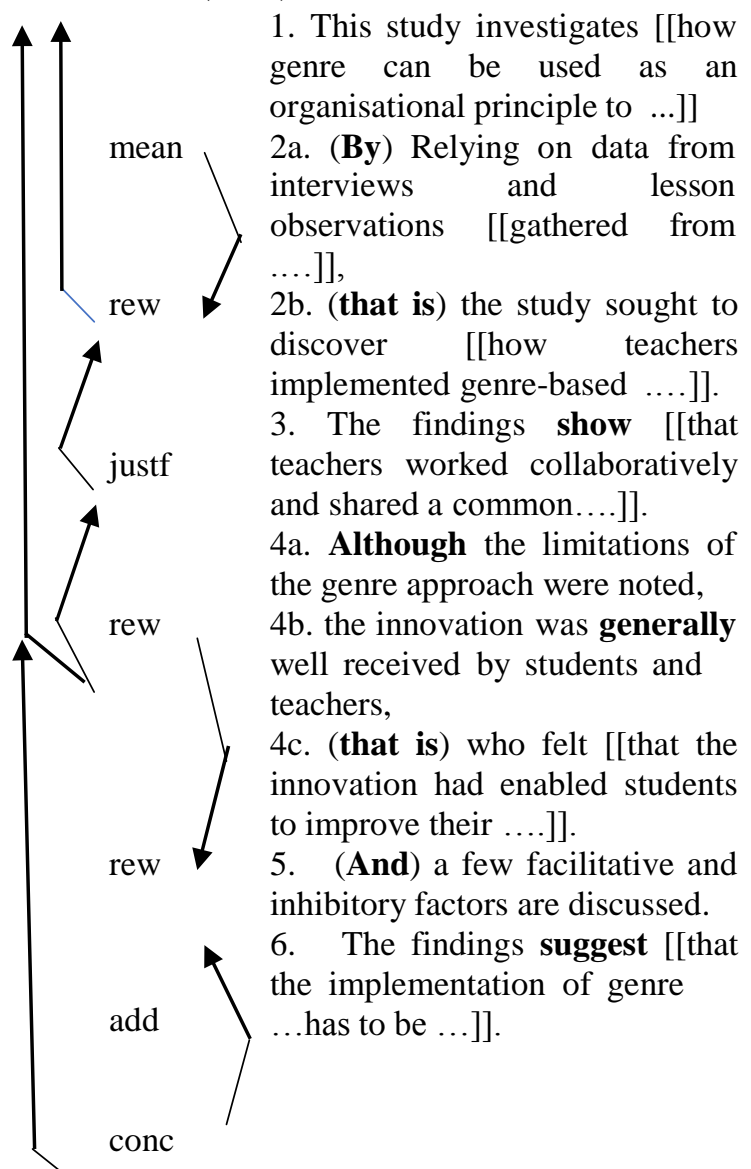

Figure 3: CR analysis on Lee's abstract (2012)

Notes: mean: means consequence; rew: rework similar comparison; just: justifying consequence; add: additive addition; conc: concluding consequence

The CR analysis can display that Lee's abstract (2012) is constructed through three stages. The stages are identified by the three internal up-facing arrows that connect groups of clauses into phases and stages of the abstract. Stage 1 is constructed in two phases realized in clause 1 and 2. Clause 1 expresses the focus of the study, resulting in the first phase in stage 1 . Meanwhile, phase 2 is realized in clause 2 that combines the method and objective of the research in a clause complex $2 \mathrm{a}$ and $2 \mathrm{~b}$. Clause $2 \mathrm{a}$ indicates the method of the research connecting the following clause by using external means consequence implicit CR (By). The internal rework similar implicit $\mathrm{CR}$ (that is) in clause $2 \mathrm{~b}$ together with 2a elaborates the focus of the research in clause 1.

Thus, the left up-facing arrow in clause $2 b$ connects clause $1,2 \mathrm{~b}$, and $2 \mathrm{a}$ all together to make up stage 1 that contain focus, method and objective of the research. Stage 2 is also developed from two phases. Phase 1 comprises of clauses 3 to $4 \mathrm{~b}$, whereas phase 2 is realized by clause 5 . Phase 1 is built from an argument realized in internal justifying consequence logic as identifying process in a projecting clause show in clause 3 to indicate the main finding in the form a token-value construction in transitivity. The finding is elaborated by internal rework similar comparison internal conjunction generally in clause $4 \mathrm{~b}$ and internal rework similar comparison implicit $\mathrm{CR}$ (that is) in clause $4 \mathrm{c}$, which is interrupted by an external concessive cause consequence conjunction Although in clause 4a that functions as a topical marked theme for clause $4 \mathrm{~b}$ and $4 \mathrm{c}$. This ends the first phase of stage 2 . Phase 2 is built up only by a clause external adding implicit addition CR (And) in clause 5, adding that a few facilitative and inhibitory factors are discussed. Finally, stage 1 and stage 2 are connected to stage 3 by a left up-facing arrow of internal concluding consequence logic as verbal process in a projecting clause suggest in clause 6 to conclude the focus, objective, and findings depicted in the previous stages. This confirms the previous findings (Martin \& Rose, 2007; Santosa, 2011).

\section{CONCLUSION}

The findings and discussion clearly indicate that neutral addition continuative and rework, justify, and conclude concluding consequence logic as process, operating in projecting clauses can operate both as external and internal function of CR. Thus, this finding can modify Martin and Rose's classification of CR, particularly in that continuative and logical metaphor can function as both external and internal CR. The finding will also encourage a modified way of analyzing texts, in which external and internal continuative and logical metaphor can operate by

themselves, in which the meanings are not necessarily being interpreted implicitly into conjunction. They have an equal access to be resources of external and internal CR to operate in the field of discourse.

The classification of continuative and logic as process may develop since other continuatives such as persistent time still, repetitive time again, more than comparison even, and less than comparison only or just and other logic as process seem to have the potentials to operate both externally and internally in the field of discourse. More abundant data may make it possible to the appearance of the continuative and logical metaphor.

\section{ACKNOWLEDGEMENTS}

The authors would like to thank the Head of the Research and Community Services (Lembaga Penelitian dan Pengabdian kepada Masyarakat) Universitas Sebelas Maret 
Surakarta. We also thank to anonymous reviewers in the Journal of English Educators Society for their valuable comments to revise the article.

\section{REFERENCES}

Alyousef, H. S. (2016). A multimodal discourse analysis of the textual and logical relations in marketing texts written by international undergraduate students. Functional Linguistics, 3(1), 1-29. https://doi.org/10.1186/s40554-016-0025-1

Darmi, R. \& Albion, P. (2014). A review of integrating mobile phones for language learning. Paper presented at the 10th International Conference Mobile Learning. https://eric.ed.gov/?id=ED557201

Devrim, D. Y. (2015). Grammatical metaphor: What do we mean? What exactly are we researching? Functional Linguistics, 2(1). https://doi.org/10.1186/s40554-0150016-7

Dreyfus, S., \& Bennett, I. (2017). Circumstantiation: taking a broader look at circumstantial meanings. Functional Linguistics, 4(1). https://doi.org/10.1186/s40554-0160036-y

Grbich, C. (2007) Qualitative data analysis: An introduction. London: Sage Publication.

Halliday, M. A. K., \& Matthiessen, C. M. I. M. (2013). Halliday's introduction to functional grammar: Fourth edition. In Halliday's Introduction to Functional Grammar: Fourth Edition. https://doi.org/10.4324/9780203431269

Hasan, R. (2014). Towards a paradigmatic description of context: Systems, metafunctions, and semantics. Springer: Functional Linguistics. 1 (9). 1-54.

Ignatieva, N., \& Rodríguez-Vergara, D. (2015). Verbal processes in academic language in Spanish: exploring discourse genres within the systemic functional framework. Functional Linguistics, 2(1). https://doi.org/10.1186/s40554-015-0014-9

Jan, J. M. \& Omar, Nor A. M. (2013). Humour in meetings: A case study of power in the Malaysian academic context. Pertanika: Social Sciences and Humanities. 21 (S). $103-116$.

Lecompte-Van Poucke, M. (2016). Exploiting the 'non-dit' and other discursive tactics in the New Caledonian independence debate: a pragma-functional approach to critical discourse analysis. A SpringerOpen Journal: Functional Linguistics. 3 (2). 1-30.

Lee, I. (2012). Genre-based teaching and assessment in secondary English classrooms. English teaching: Practice and Critique. 11 (4). 120-136.

Liddicoat, A.J. (2009). Communication as culturally contexted practice: A view from intercultural communication. Australian Journal of Linguistics. 29 (1). 115-133.
Martin, J.R., \& Rose, D. (2007). Working with discourse: meaning beyond the clause. In British Library Catalogoing 20(1). https://doi.org/10.1590/s010244502004000100011

Martin, J. R. (2014) Evolving systemic functional linguistics: beyond the clause. A SpringerOpen Journal: Functional Linguistics. 1 (3). 1-24.

Martin, J.R. (2008). Incongruent and proud: de-vilifying 'nominalization'. Discourse \& Sciety. 9 (6). 827-836.

Martin, James R. (2014). Evolving systemic functional linguistics: beyond the clause. Functional Linguistics, 1(1), 3. https://doi.org/10.1186/2196-419x-1-3

Martin, J.R., Matthiessen, C.M.I.M., \& Painter, C. (2010). Deploying Functional Grammar. Beijing: The Commercial Press.

Martin, J. R. Martin \& Rose, D. (2007). Working with discourse: meaning beyond the clause. Bloomsbury. Matthiessen, C.M.I.M., Kashyap, A.K. (2014). The construal of space in different registers: an exploratory study. Language and Science. 45. 1-27.

Matthiessen, C.M.I.M. (2015a) Register in the round: registerial cartography. A SpringerOpen Journal: Functional Linguistics. 2 (9). 1-48.

Matthiessen, C.M.I.M (2015b) Modelling context and register: the long-term project of registerial cartography. Letras, Santa Maria. 25 (50). 15-90.

Nababan, M.R., Santosa, R., Budiharjo, B. \& Dzakiria , H. (2016). Eliciting genre-based translation model from Indonesian into English. Advanced Science Letters, 22 (12) 4444- 4447.

Naderi, S., Yuen, Chee Keong, \& Latif, Hafizah. (2013). Conjunctive ties in conference proceeding of EFL Persian graduate students. Social Sciences \& Humanities. 21 (s). 13-28.

Porcu, G., Roger, V., Jacquier, A., Mazouni, C., Rojat-Habib, M. C., Girard, G., ... \& Gamerre, M. (2005). Uterus and bladder necrosis after uterine artery embolisation for postpartum haemorrhage. BJOG: An International Journal of Obstetrics \& Gynaecology, 112(1), 122-123.

Santosa, R. (2011). Logika wacana: Analisis hubungan konjungtif dengan pendekatan LSF. Surakarta: UNS Press.

Santosa, R. (2010). Bentuk dan makna metafora logikal dan pengaruhnya terhadap gaya bahasa. Kajian Linguistik Dan Sastra, 22(2), 183-192.

Santosa, R., Priyanto, A.D., Nuraeni, A., \& Dzakiria, H. (2016). The language of mass street protests in Indonesia. Advance Science Letters. (22) 16. 43934396.

Santosa, R., Priyanto, A.D., \& Nuraeni, A. (2014). Genre and register of antagonist's language in media: An appraisal study of Indonesian newspapers. Kata. (16) 1. 
23-36.

Santosa, R., Priyanto, D.P., \& Nuraeni, A. (2011). Bahasa demokratis dalam media televisi Indonesia. Lingua: Jurnal Bahasa dan Sastra. 6 (3). 227-240.

Spradely, J.P. (2007). Metode etnografi (M. Z. Elizabeth, Trans.) (2nd Ed.). Yogyakarta: Tiara Wacana.

Stuart-Smith, V. (2007). The hierarchical organization of text as conceptualized by rhetorical structure theory: A systemic functional perspective. Routledge: Australian Journal of Linguistics. 27 (1). 41-61.

Taboada, M. (2011). Stages in an online review genre. Text and Talk, 31(2), 247-269. https://doi.org/10.1515/TEXT.2011.011
Trebits, A. (2009). The most frequent phrasal verbs in English language EU documents-A corpus-based analysis and its implications. System, 37(3), 470-481. Verikaite, Daiva. (2005). Variations of conjunctive discourse markers across different genres. Zmogus ir Zodis. 7 (3). 68-75.

Conflict of Interest Statement: The authors declare that the research was conducted in the absence of any commercial or financial relationships that could be construed as a potential conflict of interest.

Copyright (C) 2021 Riyadi Santosa, Sumarlam, Tri Wiratno, Agus Dwi Priyanto, Ratna Susanti. This is an open-access article distributed under the terms of the Creative Commons Attribution License (CC BY). The use, distribution or reproduction in other forums is permitted, provided the original author(s) and the copyright owner(s) are credited and that the original publication in this journal is cited, in accordance with accepted academic prac- tice. No use, distribution or reproduction is permitted which does not comply with these terms. 